\title{
Derechos económicos, sociales y culturales como límites a las políticas públicas: el caso del derecho a la educación en Chile*
}

\section{Economic, social and cultural rights as a public policy limits: the case of the right to education in Chile}

SUMARIO

Preliminar. I. Sobre la legitimidad de un gobierno democrático. II. Aproximación a las políticas públicas. III. El monopolio neoliberal de las políticas públicas. IV. La formación de una industria de la educación en un contexto de mercado universitario. $\mathrm{v}$. Los derechos económicos, sociales y culturales como límite jurídico a las políticas públicas. vi. El desafío al pensamiento y la reflexión económica: una economía al servicio de los derechos sociales, económicos y culturales.

RESUMEN

Respecto de la legitimidad democrática de un gobierno se ha convertido en un lugar común sostener que la elección por los ciudadanos de un determinado conglomerado para que asuma el gobierno (principio democrático) dota a este de la legitimidad necesaria y suficiente para implementar políticas públicas que su programa o la contingencia política vayan exigiendo. La cuestión que se aborda es si la política pública tiene o no límite en los derechos humanos.

* Recibido el 10 de octubre de 2014, aprobado el 11 de febrero de 2015.

Para citar el artículo: E. E. Palma G. y S. SANTos P. Derechos económicos, sociales y culturales como límites a las políticas públicas: el caso del derecho a la educación en Chile. Revista Derecho del Estado n. ${ }^{\circ}$ 34, Universidad Externado de Colombia, enero-junio de 2015, pp. 237 254. DOI: 10.18601/01229893.n34.11

** ERic E. Palma G., licenciado en Ciencias Jurídicas y Sociales, abogado y magíster en Historia. Doctor en Derecho. Director de investigación y profesor titular, cátedra de Historia del Derecho e Historia Institucional de Chile, Facultad de Derecho de la Universidad de Chile. Contacto: ericepalma@yahoo.es

Antonia Santos P., licenciada en Ciencias Políticas y Sociología, socióloga, doctora en Ciencia Política. Profesora asociada e investigadora de la Facultad de Ciencias Jurídicas y Políticas de la Universidad Arturo Prat. Contacto: asantos@unap.cl 
En concreto, se intenta responder a la pregunta de si resulta legítima y ajustada a derecho una política pública de un gobierno democrático aunque amenace o lesione derechos sociales, económicos y culturales. Específicamente, se intenta responder a la cuestión de si es legítima y ajustada a derecho una política pública que no financie la educación superior estatal universitaria y no establezca la gratuidad de la educación superior en Chile, siendo esta una de las demandas sociales más importante en los últimos años.

PALABRAS CLAVE

Políticas públicas, educación, derechos humanos, legitimidad, Chile.

\section{ABSTRACT}

Concerning to the democratic legitimacy of a government it has become a common place to hold that the election by the citizens of a particular conglomerate to assume the government (democratic principle) gives it the legitimacy necessary and sufficient to implement public policies that its program or political contingency go demanding. The issue in discussion is whether public policy has or has not limit in human rights. Specifically, it will try to answer the question of whether it is legitimate and accordance with the law a public policy of a democratic government even though it threatens or injures social, economic and cultural rights. Specifically, we attempt to answer the issue whether it is legitimate and accordance with the law a public policy which does not fund the higher education state university and neither does not establish free the higher education in Chile, which is one of the most important social demands in recent years.

\section{KEYWORDS}

Public policy, education, human rights, legitimacy, Chili.

PRELIMINAR

En los últimos cuatro años se ha producido en Chile la mayor movilización social desde la recuperación democrática. Dicha protesta ha tenido como protagonista al movimiento estudiantil que se ha ido posicionando como el actor clave en las demandas educativas, fortalecido por el apoyo de amplias mayorías ciudadanas. Básicamente son tres las demandas que se expresan: fin al lucro, gratuidad de la educación superior y calidad. El sistema educativo responde al modelo económico neoliberal implementado en Chile desde finales de la década de 1980, que, a pesar de haber sido objeto de importantes reformas en los últimos veinte años, aún no ha afrontado la desigualdad y 
la segregación social que genera. La educación superior en el país es cara, y hablar de educación superior pública no deja de ser una falacia. Actualmente esta demanda ciudadana ocupa un lugar destacado en la discusión nacional como política pública y es uno de los ejes centrales en las reformas propuestas por el gobierno.

\section{SOBRE LA LEGITIMIDAD DE UN GOBIERNO DEMOCRÁTICO}

El concepto democracia presenta distintas acepciones e interpretaciones, aunque no cabe duda de que la democracia entraña un principio de legitimidad (SARTORI, 2002). La primera aproximación requiere centrarse en una definición amplia de lo que se entiende por un gobierno democrático. Siguiendo a SoDARo (2004) cabe afirmar que un gobierno es democrático no solo porque ha sido elegido por una mayoría ciudadana (lo que nos pone de lleno ante la cuestión de la legitimidad de origen) sino también porque se acatan, por los gobernantes, los límites a sus poderes y se respetan y garantizan ciertas libertades y derechos, esto es, la legitimidad de ejercicio, superándose así una definición puramente operativa que sitúa como fuente de legitimidad a la soberanía popular (KELSEN, 2002). Es precisamente el principio mayoritario el eje en el que se centra el problema del ejercicio del poder democrático (SARTORI, 2002).

El binomio legitimidad de origen o formal (elecciones)-legitimidad material o funcional (es decir, la de resultados en el ejercicio del poder, y que se orienta al cumplimiento de objetivos definidos por la base legal del Estado) es lo que hay que tener en cuenta en la toma de decisiones y en la definición de las políticas públicas, sin obviar las exigencias de otras fuentes de legitimidad en el desarrollo democrático, como pueden ser la imparcialidad, la reflexividad y la proximidad (RúA, 2013; Rosanvallón, 2009).

Si bien la ilegitimidad de ejercicio de gobierno ha sido teorizada a lo largo de la historia para casos más bien extremos, la teoría sobre la dictadura no tiene una larga tradición. La dictadura o monocracia se puede entender como opuesta a la democracia, y se sustenta en un gobierno no elegido popularmente, el cual carece de base jurídica y constitucional y recurre al uso de la fuerza; es por ello que toda dictadura es un gobierno caracterizado por cuatro rasgos: la concentración del poder, la personalización de la autoridad, los mecanismos de control ciudadano y la inestabilidad o inexistencia de normas legales (SARTORI, 2002: 83).

Es así como el diccionario señala que dictadura es un "Gobierno que, bajo condiciones excepcionales, prescinde de una parte, mayor o menor, del ordenamiento jurídico para ejercer la autoridad en un país"; también se entiende como el "Gobierno que en un país impone su autoridad violando la legislación anteriormente vigente". Y por dictador: "En la época moderna, 
persona que se arroga o recibe todos los poderes políticos extraordinarios y los ejerce sin limitación jurídica" (RAE, 2014).

El contexto en que formulamos las preguntas iniciales no es el de un gobierno que ha incurrido en ilegitimidad de origen y de ejercicio, sino el de uno que, conservando su legitimidad y no arrogándose potestades que anulan a otros poderes, pretende imponer su programa de gobierno basado en que ha obtenido la mayoría suficiente para tomar decisiones e implementar sus políticas, aunque aplique políticas públicas que violan derechos.

Es entonces cuando cabe preguntarse: ¿un gobierno legítimamente elegido puede imponer una política pública que ha procurado consensuar en la comunidad, aunque ella signifique negar un derecho humano?; ¿pueden las autoridades políticas realizar estas conductas sin que se asocie a ello pérdida de legitimidad o surgimiento de responsabilidad política y jurídica?

\section{APROXIMACIÓN A LAS POLÍTICAS PÚBLICAS}

Se va a entender por política pública el diseño por parte del Gobierno de una acción intencional para dar satisfacción a una demanda colectiva que expresa intereses, necesidades, preferencias; así como el curso que efectivamente toma la acción como resultado de las muchas decisiones e interacciones que comporta y, en consecuencia, los hechos reales que la acción colectiva produce (Aguilar Villanueva, 1996).

Se señala (Ruíz y CÁrdenAs, 2005) que en el diseño e implementación de una política pública hay que atender: a las normas jurídicas que las hacen posibles; al elemento humano que las implementa o sostiene; a los recursos que se requieren para ejecutarlas; y al elemento más político, a saber, la persuasión, esto es, a la obtención por el gobierno de la aceptación de dicha decisión gubernativa por la comunidad que la ve como legítima expresión de la protección de intereses de las mayorías.

La literatura está conteste (Dávila y Soto, 2011) en que la noción de política pública como conocimiento disciplinar se incorporó en Chile en la década de 1990 como conocimiento experto controlado mayoritariamente por los economistas y su racionalidad. En tanto que conocimiento, "las políticas públicas estudian una dimensión más acotada del poder, aquella relacionada con el resultado de la lucha por el poder en una dimensión concreta y específica como son las acciones y omisiones del Estado en problemas concretos que afectan a las sociedades complejas y democráticas en el mundo contemporáneo" (DÁvila y Soto, 2011: 11).

En Chile, desde la recuperación democrática y bajo los gobiernos de la Concertación ${ }^{1}$, los economistas no solo influyeron en el diseño de las polí-

1 Coalición política de centro-izquierda que aglutinaba a cuatro destacados partidos, 
ticas sino que fueron al mismo tiempo los que enseñaron sobre las mismas: su diseño, su ejecución y su evaluación. Además,

... otra de las novedades en relación a la utilización del enfoque de políticas públicas, es que éste ha sido adoptado por los organismos internacionales como el Banco Interamericano de Desarrollo (BID), el Fondo Monetario Internacional (FMI) y el Banco Mundial (вм). Estos han dado numerosas recetas de políticas que se relacionan con la implantación y consolidación en la región del modelo de libre mercado a través del diseño y evaluación de políticas públicas específicas (por ejemplo, educación, pensiones, entre otras) [...] Vemos entonces cómo este enfoque, fortalezas más o menos, se ha convertido en un enfoque que permite discutir globalmente las acciones del Estado, como crisis económicas, déficit fiscal, reformas a la salud, educación, entre otros, pero todos bajo un mismo paradigma económico (Dávila y Soto, 2011: 15).

Las mismas autoras señalan, siguiendo a Aguilar (2006), que la expresión "política pública" debe entenderse para este binomio, como "un comportamiento propositivo, intencional, planeado, no simplemente reactivo, casual. Se pone en movimiento con el objetivo de alcanzar ciertos objetivos a través de ciertos medios: una acción con sentido" (Agullar, 2006: 24). Por otro lado, lo público se entiende en oposición a lo privado, es decir, a políticas desarrolladas por el sector privado o agentes no estatales.

Hasta ahora ha imperado en Chile, en lo que al diseño y aplicación de las políticas públicas se refiere, una práctica política que presenta dos graves limitaciones: una, se desconoce la totalidad de la normativa jurídica que ha de tenerse a la vista para su diseño; y dos, se atiende de manera muy deficiente al elemento de persuasión. Tal conducta se explica perfectamente si no se pierde de vista que el ideario económico neoliberal desconoce a ciertos derechos el carácter de tales y por tanto presta escasa atención al ciudadano para centrarse en el consumidor como destinatario.

La estrecha relación entre política y derecho, entre derechos y deberes del Estado, tiene en el contexto actual una especial connotación. Ello porque los gobernantes tienden a negar tal relación, es decir, la dimensión jurídico política de los derechos económicos, sociales y culturales (DESC), en concreto del derecho a la seguridad social, a la salud, a la vivienda y a la educación, y promueven una visión del fenómeno como un mero caso de acceso a bienes de consumo.

A veces el conocimiento económico opera de manera autónoma frente a la ciudadanía y además, defendidos por los grupos económicos o por empresarios considerados individualmente, puede ser determinante en el

entre otros: Socialista, Democratacristiano, Partido por la Democracia y Partido Radical. Dicha coalición fue gobierno durante 20 años, de 1989 a 2010. 
diseño, aprobación e implementación de la política pública al actuar como grupo de presión.

Si nos preguntamos: ¿se puede demandar por la ciudadanía que la política pública en educación se oriente a partir del derecho a la educación?, ¿puede ser transformado el derecho a la educación en la vara de medida de la política pública en la materia?

Para desarrollar estas cuestiones se tendrá en cuenta: el monopolio neoliberal de las políticas públicas; la formación de una industria de la educación en un contexto de mercado universitario; los derechos económicos y sociales como límite jurídico a la política pública controlada por el neoliberalismo; y, el desafío al pensamiento y la reflexión económica: una economía al servicio de los derechos sociales, económicos y culturales.

\section{EL MONOPOLIO NEOLIBERAL DE LAS POLÍTICAS PÚBLICAS}

Dada la ideología económica dominante en Chile, ha venido ocurriendo que criterios exclusivamente empresariales resultan ser determinantes a la hora de generar políticas públicas. Parece existir una suerte de monopolio a favor de los economistas neoliberales en su diseño, aprobación e implementación.

El empresario que promueve el libre mercado se caracteriza, de acuerdo con las descripciones de los propios defensores de la economía neoliberal, por su egoísmo, por perseguir la obtención de la máxima ganancia y por su afán de competencia. Del despliegue de estos tres elementos, según dicha doctrina, surge el desarrollo de los países.

Los economistas neoliberales se han preguntado cómo aumentar la eficiencia de la "productividad total de factores" (el denominado residuo): ¿cómo se hace para que la productividad total de factores contribuya al crecimiento? La literatura se inclina por sostener que ello es posible: uno, a través de la promoción de una mejor utilización de los recursos, que se manifiesta como innovación o como reducción de costos (tras el objetivo de tener más utilidades, ganar más porcentajes de mercado, las empresas buscan "a lo menos mil y una modalidad para reducir costos"); y dos, a través de determinadas políticas públicas. Se sostiene, entonces, que la productividad total de factores puede ser estimulada por políticas económicas que provoquen los llamados "círculos virtuosos".

En un artículo publicado el año de 2003, el exministro CRISTIAN LARROULET se preguntaba: “¿Cuáles son las políticas públicas que inducen a ese aumento de factores productivos y que estimulan a los países a hacer un mejor uso de éstos?" (LARRoulet, 2003: 164). Defendiendo los intereses de sus mandantes (actuales o potenciales) y regularmente los propios, los economistas que están al servicio del neoliberalismo reclaman políticas públicas donde estén presentes, entre otros, los siguientes elementos: 1. Garantía de protección 
de la propiedad privada; 2. Existencia de un mercado libre en el que se dé la interacción económica y la asignación de recursos: "Son las oportunidades de ganancia personal que estimula el mercado libre, las que a su vez producen bienestar a toda la población y satisfacen el bien común de progreso" (LARroulet, 2003: 165); 3. Estados de tamaño limitado; 4. Una economía abierta al comercio internacional; 5 . Un uso más eficiente de los factores productivos (capital y fuerza de trabajo: capital humano). Ello implica una reducción de los costos del empleo de mano de obra, aunque se exige de esta que sea de calidad (de ahí la importancia de la educación y de la salud); 6. No cuestionar las ganancias extraordinarias de los empresarios, lo que incide en la política de impuestos.

Demandan también que se preserven los equilibrios macroeconómicos, entre otras, en relación con bajas tasas de inflación, equilibrio fiscal y calidad del gobierno. Decía a este respecto LaRroulet: "Contribuyen también a malos resultados, gobiernos débiles, tanto por razones políticas como por la baja calidad de sus equipos humanos, ya que las presiones de grupos de interés reducen la calidad de las políticas públicas" (LARROULET, 2003: 167)

IV. LA FORMACIÓN DE UNA INDUSTRIA DE LA EDUCACIÓN

EN UN CONTEXTO DE MERCADO UNIVERSITARIO

¿Cómo es que la actividad universitaria y de formación técnico-profesional se transformó en un área de interés para los empresarios? SALAS (2013) afirma que el mercado universitario chileno mueve dos billones de dólares, siendo financiado en un porcentaje relevante por los propios estudiantes, lo que los convierte, junto con sus familias, en inversionistas de capital humano. Los ingresos por aranceles son de 1,3 billones mientras que el aporte fiscal es solo de 0,19 billones.

¿Por qué resulta tan relevante para el empresariado la promoción de la idea de mercado universitario? La instalación en la opinión pública de la idea de "mercado universitario" cabe entenderla como una operación más o menos exitosa de los empresarios y economistas neoliberales para terminar influyendo en el diseño de la política pública en materia educacional. De esta manera esperan lograr el máximo de utilidades. Ya sabemos que ellas son el motor de su actividad y que para garantizarlas se requiere instalar un conjunto de reglas invariables que incentiven la inversión.

Los medios de comunicación y particularmente la prensa han proclamado esta situación. El diario La Tercera, en varias editoriales, y también $E l$ Mercurio han defendido el mercado y el lucro, promoviendo la idea fuerza de que lo relevante es la calidad y no el lucro; así, por ejemplo, una editorial de La Tercera sostenía que "los desafíos en educación no tienen que ver con el lucro y la privatización, sino con temas como la formación y desempeño 
profesional de los profesores, las rigideces laborales del gremio docente, las atribuciones de los directores de colegios y la eficiencia del gasto público" (La Tercera, 2011) $)^{2}$. Mejorar el mercado, es decir, regularlo, no implica el abandono de este razonamiento. En la lógica de la "industria educacional" lo relevante son las utilidades y no la satisfacción del derecho a la educación. La principal razón para rechazar esta "industria de la satisfacción de derechos" es que son absolutamente contrapuestos a los intereses económicos involucrados.

La aspiración de mejor cobertura en educación tiene el obstáculo del lucro, de las utilidades, como límite. Y el mensaje es claro: únicamente se dará la educación que no afecte las utilidades proyectadas. Porque las utilidades son sagradas. No solo eso, las utilidades son la razón de existir del dueño de un capital; tal y como nos recuerdan a cada rato los economistas neoliberales, el impulso con el que se mueve el hombre en la actividad económica es intrínsecamente egoísta. Así, en este mercado universitario en el que opera una industria universitaria, la mayoría de nosotros como usuarios o trabajadores del sistema somos los que generamos dichas utilidades.

El gasto público en educación superior en los países de la OCDE llega al $1,3 \%$ de su PIB en promedio, muy lejano del $0,4 \%$ que invierte hoy Chile. Cabe recordar, por ejemplo, que en un país vecino como Brasil la Constitución dispone que el Estado debe destinar el 10\% de su PIB a educación ${ }^{3}$.

Como afirma Manuel Riesco, "en los hechos, tras haber alcanzado cerca de 7 por ciento del PIB a principios de los años 1970, hoy continúa en poco más de 4,4 por ciento del PIB. En el caso de la educación terciaria la situación es peor: Ha bajado de 0,9 por ciento del PIB hace cuatro décadas a 0,4 por ciento del PIB en la actualidad; con el agravante [de] que ese nivel educacional concentra hoy una mayor proporción del alumnado" (RIEsco, 2011)4.

\section{LOS DERECHOS ECONÓMICOS, SOCIALES Y CULTURALES \\ COMO LÍMITE JURÍDICO A LA POLÍTICA PÚBLICA}

Estamos inermes los ciudadanos frente al impulso empresarial cuyo efecto más relevante es la mercantilización del derecho a la educación. ¿Son legítimas y tienen visos de legalidad las exigencias que el movimiento estudiantil hace para que cambie este estado de cosas? Tratándose de la satisfacción de derechos, ¿tiene el diseño de la política pública alguna cortapisa o límite?

Aquella pregunta es del mismo tipo que estas: ¿podría un gobierno activar una política de medios de comunicación social que implique el cierre de la

2 Publicado en del diario La Tercera, 13 de mayo de 2011.

3 "Mientras el promedio total OCDE del gasto en educación pública es de 5\% y de 0,7\% en privada, en Chile es de 3,3\% en la educación pública y de 3,1\% en la privada. Chile tiene una participación pública más baja que cualquier país" (OCDE, 2009: 24).

4 Publicado en el diario electrónico El Mostrador, 8 de julio de 2011. 
prensa opositora, fundado en que ganó las elecciones? ¿Podría el gobierno de turno implementar una política de restauración de la pena de muerte fundado en el mismo argumento? ¿Podría un gobierno impulsar una política educacional que siga tratando a la educación como bien de consumo y no como derecho?

Para contestar adecuadamente hay que tener a la vista un conjunto de antecedentes referidos al derecho a la educación en la legislación chilena y, al mismo tiempo, el Pacto Internacional de Derechos Económicos, Sociales y Culturales (PIDESC).

\section{El derecho a la educación en el derecho chileno}

La preocupación por la educación en el Estado Republicano es prácticamente coetánea con el éxito del proceso de independencia. Ya en el año de 1813, el 13 de junio, hubo una primera manifestación legal al respecto que establecía la obligatoriedad de fundar escuelas gratuitas. Se dejó al cabildo respectivo contribuir a su financiamiento a partir de sus bienes comunes.

La normativa constitucional de 1833 estableció en el capítulo XI, "Disposiciones Generales", el deber del gobierno de ocuparse de la educación. Obligaba al Congreso Nacional a formar un plan general de educación nacional y al Ministro del Despacho a dar cuenta anualmente del estado de la educación en todo el país (en 1837 nació el Ministerio de Justicia, Culto e Instrucción Pública). Se creaba una superintendencia de educación pública a la que se encargaba inspeccionar y dirigir la enseñanza nacional bajo la dirección del gobierno.

Así, dice en el artículo 153: "La educación pública es una atención preferente del Gobierno. El Congreso formará un plan general de educación nacional y el Ministro del Despacho respectivo le dará cuenta anualmente del estado de ella en toda la República"; y en el 154: "Habrá una superintendencia de educación pública, a cuyo cargo estará la inspección de la enseñanza nacional, y su dirección bajo la autoridad del Gobierno".

La Ley de Instrucción Primaria Obligatoria dictada el 26 de agosto de 1920 determinó, en su único artículo, que la educación primaria era obligatoria, la provisión estatal y municipal gratuita, aunque solo por cuatro años. Es asî como se estableció claramente un deber estatal y se consagró indirectamente un derecho que se expresa a través del incentivo de la educación secundaria masculina entre 1920 y 1930 (INZUnZA, 2009)

Bajo la vigencia de la Constitución de 1925 se dictó la Ley 17.398 de 9 de enero de 1971, que modificando la Constitución consideraba en el artículo 10, número 7 :

Número 7. La educación es una función primordial del Estado, que se cumple a través de un sistema nacional del cual forman parte las instituciones oficiales de 
enseñanza y las privadas que colaboren en su realización, ajustándose a los planes y programas establecidos por las autoridades educacionales.

Sólo la educación privada gratuita y que no persiga fines de lucro recibirá del Estado una contribución económica que garantice su financiamiento de acuerdo a las normas que establezca la ley.

Posteriormente y bajo el gobierno de PinocheT se dictó el Acta Constitucional de septiembre de 1976 que consagró el derecho a la educación. Así como también la Carta Constitucional otorgada de 1980 estableció por su parte en el artículo 19, número 10:

El derecho a la educación. La educación tiene por objeto el pleno desarrollo de la persona en las distintas etapas de su vida. Los padres tienen el derecho preferente y el deber de educar a sus hijos. Corresponderá al Estado otorgar especial protección al ejercicio de este derecho.

La educación básica es obligatoria, debiendo el Estado financiar un sistema gratuito con tal objeto, destinado a asegurar el acceso a ella de toda la población.

Corresponderá al Estado, asimismo, fomentar el desarrollo de la educación en todos sus niveles; estimular la investigación científica y tecnológica, la creación artística y la protección e incremento del patrimonio cultural de la Nación.

Es deber de la comunidad contribuir al desarrollo y perfeccionamiento de la educación.

Los estudios históricos constatan que junto a esta modificación se produjo una disminución progresiva del gasto estatal en educación a nivel primario y secundario. La normativa vigente en materia de educación fue modificada el año 2003 y el año 2007, y constitucionalmente se consagra, en el artículo 19 , numeral 11, la libertad de enseñanza.

En Chile hay 192 instituciones de educación superior, considerando universidades, institutos profesionales y centros de formación técnica superior. De las 61 universidades, 25 son las tradicionales, agrupadas en el Consejo de Rectores de las Universidades Chilenas ( $\mathrm{CRUCH})^{5}$, y 36 son privadas (OCDE, 2009: 37).

5 El Consejo de Rectores de las Universidades Chilenas (CRUCH) está compuesto por 25 universidades denominadas "tradicionales" puesto que son establecimientos anteriores a 1981, salvo tres universidades católicas que se crean en 1991. Así, de las 25 universidades tradicionales, 16 son estatales, 6 son católicas y 3 son universidades laicas privadas (OCDE, 2009: 36). 


\section{El Pacto Internacional de Derechos Económicos, Sociales y Culturales (PIDESC)}

En 1966 se aprueba el Pacto Internacional de Derechos Económicos, Sociales y Culturales (PIDESC), comprometiéndose los Estados firmantes a promover y proteger los derechos recogidos en el Pacto, los cuales son derechos humanos "relacionados con el lugar de trabajo, la seguridad social, la participación en la vida cultural y el acceso a la vivienda, la alimentación, el agua, la atención de la salud y la educación" (onU, 2009: 4).

Chile firmó el PIDESC el 16 de septiembre de 1969 y lo ratificó el 10 de febrero de 1972. De acuerdo con la interpretación de los organismos de la ONU el Pacto se encuentra vigente en Chile desde el 3 de enero de 1976.

A nivel interno se entendió que se requería de un acto promulgatorio y fue el propio Pinochet el que en las postrimerías de su gestión, en 1989, promulgó el PIDESC. De acuerdo con dicho Pacto, que es norma jurídica vigente en Chile, y por ende exigible, el Estado debe propender a la gratuidad de la educación superior.

Por su parte, el artículo 5. e la Constitución dispone a este respecto: "El ejercicio de la soberanía reconoce como limitación el respeto a los derechos esenciales que emanan de la naturaleza humana. Es deber de los órganos del Estado respetar y promover tales derechos, garantizados por esta Constitución, así como por los tratados internacionales ratificados por Chile y que se encuentren vigentes".

Conviene tener a la vista también la Convención relativa a la Lucha contra las Discriminaciones (ratificada por Chile en 1971) que en su artículo primero entiende por discriminación "toda distinción, exclusión, limitación o preferencia fundada en la raza, el color, el sexo, el idioma, la religión, las opiniones políticas o de cualquier otra índole, el origen nacional o social, la posición económica o el nacimiento, que tenga por finalidad o por efecto destruir o alterar la igualdad de trato en la esfera de la enseñanza".

Es ya una cuestión no debatida que la aplicación de las disposiciones del PIDESC, a nivel nacional e internacional, es una obligación jurídica para sus Estados parte. Esto significa que el PIDESC tiene fuerza de ley.

En atención a la normativa del PIDESC el derecho a la educación presenta las siguientes características: a) Es un fin en sí mismo: "Desde la perspectiva de los derechos humanos, la educación es, por lo tanto, un fin en sí misma y no un simple medio para conseguir otros fines"; b) Como se señala en la Observación General número 3, se trata de un derecho con múltiples dimensiones, por lo que debe tratarse como derecho económico, social y cultural y derecho civil y político; de acuerdo con la Observación General número 13 de 1999 se caracteriza por su c) disponibilidad; d) accesibilidad; e) aceptabilidad; f) adaptabilidad. 
Como se ha señalado, el PIDESC es un instrumento jurídico internacional. Esto significa que cuando un Estado lo ratifica o se adhiere a él, se compromete a garantizar el ejercicio de los derechos que en él se enuncian. Los organismos internacionales han establecido respecto de los derechos civiles y políticos, así como de los derechos económicos, sociales y culturales, obligaciones genéricas:

... la obligación de respetar, que consiste en abstenerse de impedir u obstaculizar la realización de los derechos de las personas; la obligación de proteger, que consiste en adoptar las medidas para evitar que terceras personas puedan restringir o anular los derechos humanos de otras personas y, la obligación de realizar, la cual consiste en adoptar las medidas positivas para garantizar que las personas puedan acceder al ejercicio de sus derechos humanos, aún y cuando no puedan hacerlo por sus propios medios y recursos.

Podemos además identificar las siguientes obligaciones específicas (NúÑEZ, 2005: 149-150):

1. No discriminar en el ejercicio del derecho;

2. Adecuar el marco legal para posibilitar su ejercicio;

3. Proveer recursos judiciales y otros recursos efectivos para garantizar su vigencia;

4. Producir y publicitar información sobre el derecho a la educación;

5. Obligación de satisfacción; incluye la progresividad y su correlativa prohibición de regresividad, es decir, impone mantener los niveles ya alcanzados de satisfacción del derecho;

6. Obligación de respeto, que consiste en la no interferencia del Estado en la libertad de acción y uso de los recursos propios de las personas para satisfacer el derecho;

7. Obligación de protección, impidiendo que las personas naturales o jurídicas (empresas nacionales e internacionales) violen el derecho;

8. Sancionar los delitos de los servidores públicos y particulares en los casos de corrupción que obstaculizan la realización y violan el derecho a la educación;

9. Destinar el máximo de los recursos disponibles para su satisfacción;

10. Obligación de adoptar una estrategia nacional en que se definan los objetivos para el desarrollo de las condiciones de acceso, se determinen los recursos dis- 
ponibles para alcanzar estos objetivos, la forma eficaz y equitativa para emplear los recursos, metas claras de avance con sistema de monitoreo y verificación;

11. Garantizar la protección de los sectores en situación de vulnerabilidad;

12. Tener información disponible y clara con indicadores actualizados que permitan saber cuál es la situación de respeto del derecho, pudiendo así adoptar y conducir políticas públicas para su realización.

Que se trata de obligaciones jurídicas cuya violación implica responsabilidad es hoy día una cuestión no discutida a nivel internacional. De hecho la aprobación en el año de 2008 del Protocolo Facultativo del PIDESC refuerza este carácter.

Se ha interpretado a través de la Observación General número 3 del Comité DESC que la expresión empleada en el PIDESC, relativa a que la obligación del Estado es alcanzar progresivamente la satisfacción de los DESC y hasta el máximo de los recursos de que disponga, no constituye una causal para justificar la inacción. Lo que el Tratado señala es que:

... aunque se demuestre que los recursos disponibles son insuficientes, sigue en pie la obligación de que el Estado Parte se empeñe en asegurar el disfrute más amplio posible de los derechos pertinentes dadas las circunstancias reinantes. Más aún, de ninguna manera se eliminan, como resultado de las limitaciones de recursos, las obligaciones de vigilar la medida de la realización, o más especialmente de la no realización, de los derechos económicos, sociales y culturales y de elaborar estrategias y programas para su promoción.

Incluso en un contexto de carencia de recursos, ha dicho el Comité, en su Observación General número 3, el Estado debe velar por que se alcancen los contenidos mínimos o niveles esenciales de disfrute del derecho.

Se ha señalado al respecto:

La prohibición de regresividad en las condiciones económicas, sociales y culturales de un país es parte del principio de progresividad, pues busca también limitar las situaciones que causan un retroceso con relación a los logros ya obtenidos. Tampoco es una obligación absoluta [...] una regresión en cuanto a las condiciones económicas, sociales y culturales de la población no es necesariamente una violación del principio de no regresividad, siempre y cuando el Estado siga utilizando el máximo de los recursos disponibles. Por otro lado, también se producen ciertas situaciones excepcionales en las que el Estado puede limitar formalmente los DESC, con relación a las protecciones establecidas por las leyes y la Constitución de un país. Acerca de esta posibilidad, el mencionado Comité ha dicho que "todas las medidas de carácter deliberadamente retroactivo en este aspecto requerirán la consideración más cuidadosa y deberán justificarse plenamente por 
referencia a la totalidad de los derechos previstos en el Pacto y en el contexto del aprovechamiento pleno del máximo de los recursos de que se disponga". Por lo tanto, retrocesos en los logros alcanzados acerca de los DESC se pueden considerar violaciones de los deberes estatales, siempre que no se puedan justificar como estrictamente necesarios.

Es claro que

La pobreza no puede ser una excusa para la inacción. El Comité mantiene que un Estado signatario de un pacto "tiene que demostrar que ha desplegado todos los esfuerzos para movilizar los recursos de que dispone para satisfacer prioritariamente" sus obligaciones mínimas. Cuando examina si un Estado ha respetado o no un derecho, el Comité puede tratar de determinar si: el gobierno en cuestión ha hecho un uso eficaz y equitativo de sus recursos; el acceso a sus servicios es el mismo para todos los ciudadanos; entre todas las medidas tomadas, se ha dado prioridad a las que son necesarias respecto a estos derechos.

Reafirmando el Comité la existencia de obligaciones de ejecución inmediata identifica el deber jurídico de no discriminación como un ejemplo. Al respecto en la Observación General número 20 se indica que es un motivo de discriminación la situación social y económica de las personas. Afirmando que estamos en presencia de un caso sistemático cuando: "las normas legales, políticas, prácticas o las actitudes culturales predominantes en el sector público o privado generan desventajas comparativas para algunos grupos y privilegios para otros".

Esto quiere decir entonces que es posible sostener que una política pública puede ser violatoria del derecho a la educación consagrado en el PIDESC. Esta constatación, como ya hemos visto, está en pugna con el discurso dominante. Se ha convertido en un lugar común en la política y en el derecho chileno el tratar el derecho a la educación como fenómeno económico y no jurídico. Esto implica que la educación es enfocada como un bien económico que se transa en el mercado y respecto del cual se verifica una oferta y una demanda, siendo absolutamente admisible, e incluso deseado, que se pague un precio por el acceso a este bien.

\section{EL DESAFÍO AL PENSAMIENTO Y LA REFLEXIÓN ECONÓMICA: \\ UNA ECONOMÍA AL SERVICIO DE LOS DERECHOS SOCIALES, ECONÓMICOS Y CULTURALES}

La propuesta gubernamental respecto del sistema educacional así como el debate que ha venido generando usa un determinado lenguaje, el de la racionalidad económica neoliberal. La propuesta gubernativa adopta el enfoque de bienes, oferta, demanda, satisfacción del cliente. Así, se refiere a la educación 
como un bien público, a los "bienes públicos" que genera la educación, al mercado universitario, a financiar la oferta o financiar la demanda, etc.

La demanda ciudadana no es de perfeccionamiento del mercado, el problema de la educación chilena no es si puede o no un particular proveer lo que los economistas llaman bienes públicos. La cuestión a debatir es si el gobierno y el Estado está o no cumpliendo con su deber jurídico y político de satisfacer el derecho a la educación.

Numerosos estudios y publicaciones promueven una comprensión de la actividad de la educación superior como si fuese un mercado. Se habla incluso del mercado universitario y de la compra y venta de instituciones de educación superior como si se tratase de fenómenos estrictamente económicos.

El Relator Especial para el Derecho a la Educación, señor VERNOR MuÑoz ViLlalobos, ha sido muy claro en señalar que el derecho a la educación impide que la educación sea vista como un bien de consumo (MuÑoz, 2010).

Por otra parte la Conferencia Mundial de la Educación Superior ha resuelto que la educación no puede quedar sujeta a las reglas de las "fábricas de grado" (UNESCO, 2009).

Como nos enseña ÖZDEN, numerosos textos de la ONU subrayan la primacía de los derechos humanos sobre los acuerdos económicos; así la Subcomisión de la Promoción y la Protección de Derechos Humanos recuerda a todos los gobiernos "la primacía de las obligaciones relativas a los derechos humanos en virtud del derecho internacional, por encima de las políticas y acuerdos económicos, y les pide que tengan plenamente en cuenta, en la instancias económicas nacionales, regionales e internacionales, las obligaciones y principios internacionales relativos a los derechos humanos cuando formulan políticas económicas internacionales" (ÖZDEN, 2006: 5)

El Comité de Derechos Económicos Sociales y Culturales (CODESC), con ocasión de la tercera Conferencia Ministerial de la Organización Mundial del Comercio, invita encarecidamente a esta organización a "emprender un examen de toda la gama de políticas y normas internacionales de comercio e inversiones, a fin de asegurar que sean compatibles con los tratados, la legislación y las políticas vigentes encaminados a proteger y promover todos los derechos humanos" (ÖZDEN, 2006: 5).

En términos prácticos esto implica que la política pública que se impulsa y aprueba por el gobierno en materia de educación no puede privilegiar la visión de la misma como un bien transable en el mercado educacional. Hacerlo constituye una seria amenaza para la eficacia de la vigencia del derecho a la educación y podría ser constitutiva de una violación al deber jurídico del Estado de propender a la gratuidad del acceso a la educación en sus distintos niveles.

Además, se ha establecido en este aspecto una clarísima vinculación entre el financiamiento privado de la educación y la pobreza, de tal forma que 
cuando las familias son responsables de la educación aumenta la diferencia entre ricos y pobres (UNESCO, 2004).

Lo mismo se ha planteado respecto a la relación entre educación de pago e igualdad:

Una mirada al último medio siglo muestra que movimientos poderosos se opusieron a la segregación racial y lograron que se prohibiera la discriminación racial y se impusiese a los gobiernos la obligación de eliminarla. Sin embargo, en lugar de desaparecer, la segregación ha cambiado. Los límites de la pertenencia ya no se establecen en la ley, sino que quedan determinados por el poder adquisitivo y se pone de manifiesto en el perfil racial de la segregación residencial y en la matriculación de las escuelas privadas (onu, 2004: 26).

El caso de la educación primaria analizado por la Relatoría Especial muestra la amenaza que presenta para el derecho a la educación el libre mercado:

Uno de los principales motivos para incluir la educación entre los derechos humanos era que su realización no dependiese del mercado libre, donde el acceso a la educación está determinado por el poder adquisitivo. Las dificultades recientes para mantener este principio han determinado un cambio en el vocabulario; el derecho a la educación se ha sustituido por el acceso a la educación y la obligación de los gobiernos de velar por que al menos la enseñanza obligatoria sea gratuita se ha atenuado colocando la palabra gratuita entre comillas (educación "gratuita") [...] La base del derecho a la educación es un sistema en el que la educación sea gratuita en los lugares donde se imparte, como ejercicio de un derecho y no en función de la capacidad de cada uno para costeársela [...] [E]sta diferencia es esencial desde la perspectiva de los derechos humanos porque el libre comercio no contempla ninguna salvaguardia para los derechos de los pobres (ONU, 2004: 6)

En Chile distintos gobiernos y los economistas neoliberales han insistido en desconocer este fenómeno y defender el pago y el lucro, demonizando la intervención del Estado como proveedor de servicios educativos gratuitos. En palabras de LÜDERS (2011), "el lucro, entendido como ganancia legítima que obtiene el dueño de un establecimiento educacional privado, contribuye a asegurar la oferta marginal óptima de educación en sus distintos niveles y tipos. Finalmente, el Estado es el gestor clave que, mediante regulaciones, garantías y subsidios, articula todo el sistema para lograr que cumpla con

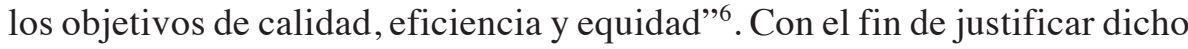
lucro se ha puesto énfasis en que lo relevante es la calidad del servicio, discurso presente en la llamada industria universitaria y las esferas del gobierno.

6 En artículo de opinión publicado en el diario La Tercera, Rolf LüDERs, "El financiamiento de la educación”, Santiago, 19 de agosto de 2011. 
A mayor abundamiento cabe señalar que los organismos internacionales de derechos humanos están habilitados para evaluar la política pública. Cuestión que en relación con el derecho a la educación ha sido defendida por la Relatoría Especial:

... la Relatora Especial tiene intención de llevar a cabo un análisis completo de la evolución de las políticas y los modelos de ayuda para la educación como manera de aumentar la capacidad de los gobiernos a fin de que cumplan sus obligaciones con respecto al derecho a la educación [...] La labor de los gobiernos consiste en elaborar una estrategia de educación, regular la enseñanza fijando y aplicando normas mínimas, llevar a cabo una supervisión permanente y tomar medidas correctivas cuando proceda (ONU, 2004).

Incluso se ha resuelto que los tribunales internos cuentan con esta potestad:

En Brasil, el Tribunal Supremo Federal consideró en 2005 que el Estado estaba obligado a garantizar el acceso a las guarderías y los jardines de infancia a los niños de entre 0 y 6 años de edad de conformidad con la Constitución. Se recurrió al Tribunal en relación con ese asunto en el marco de una acción civil pública sobre el derecho a la educación de los niños. El Tribunal subrayó que, en las situaciones en que los poderes administrativos no protegían los derechos sociales mediante políticas adecuadas de carácter público, correspondía a los tribunales proteger los derechos económicos, sociales y culturales (onU, 2009: 40).

Este es probablemente el mayor desafío que enfrentan los DESC, y el derecho a la educación en particular: romper con la idea fuerza que lo ve como el bien de consumo que produce la industria universitaria y que se vende en el mercado universitario; así como con la creencia según la cual la política pública es legítima solo porque la diseña y aplica un gobierno legítimamente elegido.

\section{REFERENCIAS BIBLIOGRÁFICAS}

Aguilar, Luis. El estudio de las políticas públicas. México, Miguel Ángel Porrúa, 1996.

Dávila, Mireya y Soto, Ximena. “¿De qué se habla cuándo se habla de políticas públicas? Estado de la discusión y actores en el Chile del bicentenario", en Estado, Gobierno, Gestión Pública n. ${ }^{\circ}$ 17, 2011, Santiago de Chile, Instituto de Asuntos Públicos, Universidad de Chile, 2011, pp. 5-33.

INZUNZA, JoRge. La construcción del derecho a la educación y la institucionalización de la educación en Chile. Santiago, Opech, 2009.

Kelsen, Hans. Esencia y valor de la democracia. Granada, Comares, 2002.

Laurroulet, Cristian. "Políticas públicas para el desarrollo", en Estudios Públicos n. 91. Santiago, 2003, pp. 153-179. 
Muñoz, Vernon. El derecho a la educación: una mirada comparativa. Santiago, Oficina Regional de Educación para América Latina y el Caribe, Unesco, 2010.

Özden, Malik. Por un protocolo del PDESC. Programa Derechos Humanos de Centro Europa-Tercer Mundo. Ginebra, сетIM, 2006.

Rosanvallón, Pierre. La legitimidad democrática: imparcialidad, reflexividad, proximidad. Buenos Aires, Manantial.

RÚA, CARlos. "La legitimidad en el ejercicio del poder político en el Estado social de derecho. Una revisión desde el caso colombiano", en Ius et Praxis, año 19, n. ${ }^{\circ} 2$, Facultad de Ciencias Jurídicas y Sociales, Universidad de Talca, pp. 85-122.

Ruiz, Domingo y CÁRdenas, CARlos. “QQué es una política pública?”, IUS n. . 18, Guadalajara, Universidad Latina de América, 2005, pp. 1-22.

Salas, Víctor. "El financiamiento de las universidades chilenas y futuro del sistema", Departamento de Economía, Universidad de Santiago de Chile (USACH), Serie Documentos de Trabajo, wp 2013, n. ${ }^{\circ}$ 07, Santiago, 2013.

Sartori, Giovanni. Elementos de teoría política. Madrid, Alianza Editorial, 2005.

Sodaro, Michael. Política y Ciencia Política. Madrid, McGraw-Hill, 2010.

UNESCO. Una educación de calidad para todos los jóvenes. Reflexiones y contribuciones en el marco de la 47. ${ }^{a}$ Conferencia Internacional de la Educación. Ginebra, UnESCOOIE, 2004.

UNESCO. Conferencia Mundial sobre la Educación Superior: la nueva dinámica de la educación superior y la investigación para el cambio social y el desarrollo. ED. 2009/ conf. 402/2. París, UNESCO, 2009.

OCDE. Thematic review of tertiary education: Country background report for Chile. Santiago, 2007.

OCDE. La educación superior en Chile, OCDE-BIRd y Banco Mundial, Santiago, 2009.

ONU. Los Derechos Económicos, Sociales y Culturales: el derecho a la educación, Relatora Katerina Tomasevki. Consejo Económico y Social, E/CN.4/2004/45, Naciones Unidas, 2004.

ONU. Preguntas frecuentes sobre los Derechos Económicos, Sociales y Culturales. Oficina del Alto Comisionado de las Naciones Unidas para los Derechos Humanos, Folleto Informativo n. ${ }^{\circ}$ 33. Ginebra, oNU, 2009.

Uribe, Alirio. "Aprendiendo los Desc". Derechos Económicos, Sociales y Culturales. Programa de Cooperación sobre Derechos Humanos. México, Comisión Europea, 2005, pp. 121-172. 